\title{
The Similarities of Thematic Progression in Zodiac Killer Letters
}

\author{
Mohammad Rakhmat Pramudita, Elvi Citraresmana, Susi Yuliawati
}

Department of Master Linguistics, Padjadjaran University, Jatinangor, Indonesia

\begin{abstract}
This study examines thematic progression in zodiac killer letters. This study aims to reveal the unknown killer whether it is personal killer or group killer. This study employs a descriptive qualitative method since it attempts to describe and analyze textual data accurately. The data of this study come from research publication article. After gathering the data, thematic progression theory proposed by Fries (2002) is employed to analyze the data. Findings show that constant theme is the type of thematic progression that is mostly used in the zodiac killer letters by $65.30 \%$. However, some letters of zodiac killer contain a lot of similarities for instance they usually use constant theme and multiple theme but there is no linear theme. This study conclude that the similarities of thematic progression often occur in zodiac killer letters. It means that the zodiac killer letters are very possible written by one person. So it's a personal crime, not group killer.
\end{abstract}

Keywords-Letters, patterns, sfl, thematic progression, zodiac killer.

\section{INTRODUCTION}

Language as a communication tool must have a pattern and it can transfer a meaning, which are bound in grammatical structure. Grammar can be explained as a combination of linguistics unit, which produces sentences in the language (Richards and Schmidt, 2002). Grammar also on its pattern and vocabulary can be combined to tie meaning in text to make it cohesive and coherent. As mentioned by Paltridge (2006) that both cohesive and coherent texts are created through resource such as patterns of cohesion and it is understood as unity of texture. Furthermore, the elements that contribute to the texture of a text are thematic progression. Thematic progression deals with the organization of a clause or an utterance which consists of theme and rheme to form a message (Sharndarma and Panamah, 2013). The thematic progression which contains theme and rheme relationship contributes to the flow of information in the text. Thus, thematic progression is a major aspect of how the speakers or the writers construct their messages to make them into the unfolding language event (Thompson, 2014). We outline that inside of the clause include information and message, then the clause consist of theme and rheme which has some patterns. Therefore, thematic progression is a rule to make a clause which contains the types or patterns of theme and rheme. Theme is an element which come in the first clause, while rheme is an element which come after theme, or it comes in the rest of the clause. Both theme and rheme include a message and information. Furthermore, In the thematic progression there are three types or patterns in making a clause. Those types are for instance constant theme or theme reiteration, linear theme or zig-zag theme, and multiple themes or split rheme (Fries, 2002). In the presence of those types of thematic progression attract the writer's attention to solve the issues especially in written text.

Besides language as communication tool, it's also employed to write an idea in written text. Someone can write anything in their context and even possible in criminal case. For instance, in case of zodiac killer. Zodiac killer is serial killer or American serial killer, because it happens in California especially Northern California, USA. In 1960s of the Bay Area of California there was terrible history. A murderer who was extremely elusive wandering the Bay Area streets at night. Known as zodiac killer, because of his messages signed with zodiac symbol and chipers. He becomes a famous and terrifying killers in history.

The unsolving issues in zodiac killer case is the killer in this case is still unknown. One of the researcher, Raddum (2010) describes background of zodiac killer's chipper and presents the strategy to solve the chipers. His research's purpose is to know the information in the chipper of zodiac killer letters. It is the same as Raddum's research on 
zodiac killer case but it is different on the data, those are letters. Raddum takes the chipper letters while the writer is only taking general letter or plain text of zodiac killer. The writer attempts to analyze zodiac killer's letter with employing thematic progression to reveal the idea or information on each letters of zodiac killer. It supports by Fries (2002) that thematic progression as method of development of text is a tool for analysis the idea on theme and rheme. Moreover, Halliday (2014) describes about thematic progressions clause of message which contains theme and rheme to deliver idea or information inside the text. In thematic progression, the writer also interests to reveal a brain of killer whether it is personal or group killer. It means in thematic progression we know some types such as constant theme, linear theme, and multiple themes. Here the writer wants to find out those types in zodiac killer letters whether there are similarities or not. Therefore, the concept of similarity on the text as in the creation of certain text, we are constantly influenced by texts of similar kind (Ghadessy, 1995: 143).

Based on the serial killer of zodiac killer above the writer is interested to clear some issues on it, such as there are three main suspects that have been determined by the police, and also in every letters, it has different form in his handwriting. So, the writer decides to choose thematic progression which is in accordance with the issues mentioned above. The writer also attempts to clear the problem and to know what's the ideas or pattern of thematic structure on each letters of zodiac killer have similar pattern or not. The purpose of this research is to find out thematic patterns on each zodiac killer letters and also to analyze the similarity or differences on these letters, so that it can reveal the total killer on this case whether it is personal or group killer. Thus, if the result of analysis finds there are some differences thematic progression on the letter among others, it means that there is possibility the letters is written by second writer or different person. As mentioned by Ghadessy (1995) that different thematic structure in one genre compares with others means specific thematic choices are necessary for moving a particular discourse forward. In the same context of zodiac killer's letter, if the zodiac killer letters have a lot of different thematic progression, it means the killer has different point to access information in the text (Paltridge, 2006), the text refers to letters of zodiac killer. So, in this case there are more than one killer who writes zodiac killer letters because different thematic structure pattern indicates different perspective on what writer follows (Brown \& Yule, 1983). And to conclude, the crime might be done by more than one person in other words it is criminal group. Hopefully, the research also can be contributed to clear the issue of zodiac killer case as material for helping the investigators or even forensic linguists at the future.

\section{THEORY}

Paltridge (2006) argues that thematic progression refers to the way in which the theme of the clause may pick up, or repeat, a meaning from preceding theme or rheme. Thematic progression is the key to create the information in a text. According to Fries (2002) there are three form of thematic progression such as constant theme, linear theme, and multiple themes. Theme can be explained as the element which serves as point of departure of the message and rheme as the remainder of the message in which the theme is developed (Halliday and Matthiessen, 2004). Theme also can be identified as the elements which come at the beginning in a clause (Gerot and Wignell, 1994). Moreover theme indicates what the text is about. There are three categories of theme such as; ideational or topical theme, textual theme, and interpersonal theme (Gerot and Wignell,1994). Meanwhile, Yang Yan (2015) argues that thematic progression provides the benefit as, it gives a clue to choice and organization of information. There are three kinds of thematic progression patterns, they are: reiteration/constant theme pattern, zig-zag/ linear theme pattern, and multiple theme/ split rheme pattern. The three patterns can be seen below.

Table 1. Theme and rheme: constant theme (Martin \& Rothery 1986 in Paltridge, 2000:121)

\begin{tabular}{|l|l|}
\hline \multicolumn{1}{|c|}{ Theme } & \multicolumn{1}{c|}{ Rheme } \\
\hline The bat & is a nocturnal animal \\
It & lives in the dark \\
There & are long nosed bats and mouse eared \\
& bats also lettuce winged bats \\
Bats & hunt at night \\
They & sleep in the day and very shy \\
\hline
\end{tabular}




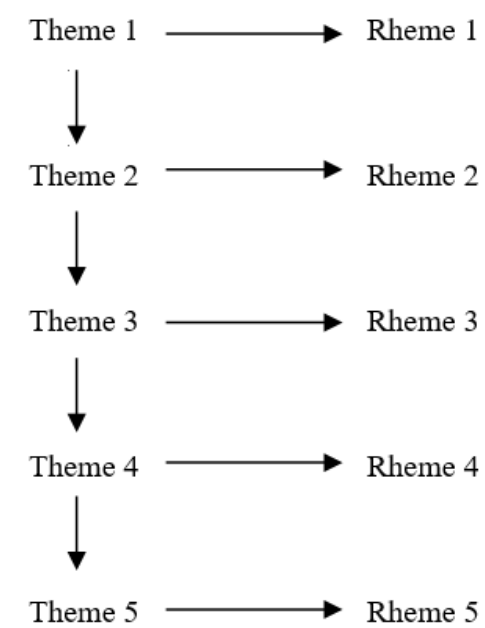

Fig.1: Thematic progression: constant theme based on table 1. (Paltridge, 2006)

From Table 1.and Figure 1 we can conclude that it shows that bat as the theme becomes the theme in second, third, fourth and fifth, as shown in Table 1.

Table 2. Theme and Rheme: Linear theme /Zig-zag theme (based on Clegg \& Wheeler, 1981:83)

\begin{tabular}{|l|l|}
\hline \multicolumn{1}{|c|}{ Theme } & \multicolumn{1}{c|}{ Rheme } \\
The American & $\begin{array}{l}\text { Specifies a documentation } \\
\text { format required by most } \\
\text { psychology, sociology, } \\
\text { communication, education and } \\
\text { economics instructions. } \\
\text { This format }\end{array}$ \\
$\begin{array}{l}\text { includes parenthical } \\
\text { documentation in the text that } \\
\text { refers to an alphabetical } \\
\text { reference at the end of the } \\
\text { chapters. }\end{array}$ \\
\hline
\end{tabular}

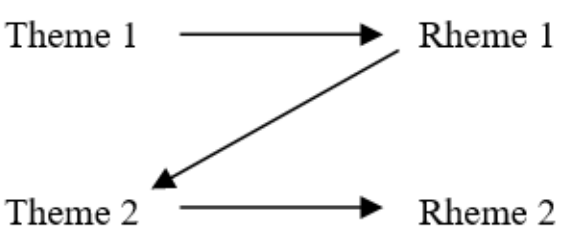

Fig.2: Linear theme/ zig-zag theme pattern (based on Clegg \& Wheeler, 1981:83)

From table 2.and figure 2 show that Rheme 1 becomes Theme 2, as a Linear theme pattern
Table 3. Theme and Rheme: Multiple theme / Split rheme (based on Nesbitt et al, 1990, cited in Paltridge 2006)

\begin{tabular}{|c|c|}
\hline Theme & Rheme \\
\hline $\begin{array}{l}\text { When Japanese } \\
\text { people }\end{array}$ & write their language \\
\hline they & $\begin{array}{l}\text { use a combination of two } \\
\text { separate alphabets as well as } \\
\text { ideograms borrowed from } \\
\text { Chinese }\end{array}$ \\
\hline The two alphabets & are called hiragana and katakana \\
\hline $\begin{array}{l}\text { The Chinese } \\
\text { ideograms }\end{array}$ & are called kanji \\
\hline Hiragana & $\begin{array}{l}\text { represents the } 46 \text { basic sounds } \\
\text { that are made in the Japanese } \\
\text { language }\end{array}$ \\
\hline Katakana & $\begin{array}{l}\text { represents the same sounds as } \\
\text { hiragana }\end{array}$ \\
\hline but & $\begin{array}{l}\text { is used mainly for words } \\
\text { borrowed from foreign language } \\
\text { and for sound effects }\end{array}$ \\
\hline Kanj1 & $\begin{array}{l}\text { are used to communicate an idea } \\
\text { rather than a sound }\end{array}$ \\
\hline
\end{tabular}


Theme $1 \longrightarrow$ Rheme 1

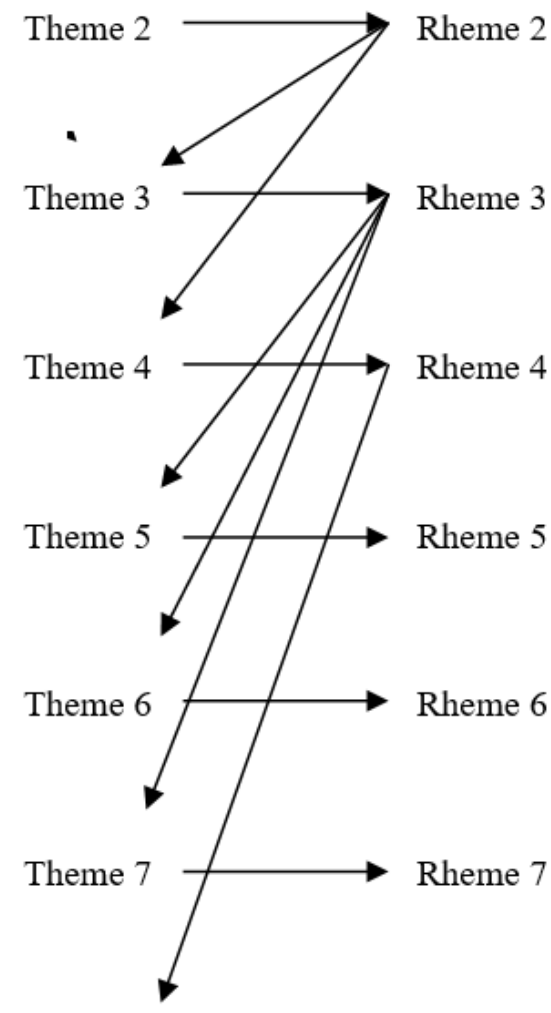

Theme 8

Rheme 8

Fig.3: Thematic progression: Multiple theme / split rheme based on Table 3 (Paltridge, 2006)

From table 3 and figure 3 it shows that only the first theme becomes theme in the second clause whereas the other themes are from the rheme. It explained that theme 2 and 3 are from rheme 2 and rheme 3 becomes theme 4 and 5 while rheme 4 becomes theme 6 .

\section{METHOD}

The present study employs a qualitative approach after considering the issue and the objective which the research proposes to carry through. Creswell (2012) stated that qualitative research is a good way to address a research problem in which you do not know the variables and need to explore. In addition, According to Saldana (2011), qualitative approach is an umbrella term for a wide variety of approaches to and methods for natural social life. Furthermore, qualitative method observes actions and structures of the preferred variable (Tracy, 2019). The explanation above attracts the writer's attention to employ a qualitative method with a descriptive approach and quantitative measurement proposed by Fries (2002, as cited Paltridge, 2006). This study attempts to analyze thematic progression pattern in zodiac killer letters in order to see how the ideas are constructed.

After obtaining the data, thematic progression theory proposed by Fries (as cited in Paltridge, 2006) is employed to analyze the data by, the first step is the researcher reads the downloaded zodiac killer letters, the second step is the researcher breaks down the zodiac killer letters into clauses. The third step is placing the clauses into table format to make the process of the analysis easier and clearer. The fourth step is determining the theme and rheme. The fifth step is classifying the thematic progression pattern, whether it is constant, linear, or multiple themes. The sixth step is calculating the occurence of each type of thematic progression patterns found in the zodiac killer letters. The last step is the researcher interprets the findings to draw a conclusion of how the zodiac killer letters present the thematic progression patterns whether they're mostly found the similarities pattern or differences pattern.

\section{FINDINGS AND DISCUSSION}

The following tables show the distribution of thematic progression patterns found in zodiac killer letters and its percentage as well.

Table 4. The distribution of thematic progression pattern

\begin{tabular}{|l|l|l|l|l|l|l|l|l|l|l|l|l|}
\hline TP Pattern / Sample & A & B & C & D & E & F & G & H & I & J & K & L \\
\hline Constant Theme & 4 & 3 & 2 & 1 & 1 & 4 & 2 & 1 & 2 & 4 & 1 \\
Linear Theme & 0 & 0 & 1 & 0 & 3 & 0 & 1 & 0 & 0 & 1 & 1 \\
Multiple Theme & 1 & 1 & 1 & 0 & 0 & 1 & 1 & 2 & 0 & 1 & 0 \\
\hline
\end{tabular}

The researcher named data zodiac killer from data one until data twelve and change with alphabet from data $\mathrm{A}$ until data $\mathrm{L}$ to make it clearer. Based on table above we can see the similarities and the differences from one data among others. For instance, the comparison between data A and data B showed that there are the similar data of thematic progression, because in those data have found constant theme and multiple theme, but there is no linear 
theme. The same context of similar theme also found in data $\mathrm{A}$, data $\mathrm{B}$, data $\mathrm{F}$, and data $\mathrm{H}$. then, if we compare the data with each other will be A-F, B-F, A-H, B-H, F-H. it means that data $A$ same with data $F(A-F)$, data $B$ same with data $F(B-F)$ and so on. It is similar because there is no linear theme in those data. So, in four data (A-B-F-H) of zodiac killer letters which has been compared each other was found that there are six similar pairs $(\mathrm{A}-\mathrm{F}, \mathrm{B}-\mathrm{F}$, A-H, B-H, F-H). Moreover, the other similarities pattern is appeared in the data which has complete thematic progression pattern, it means that all patterns has occurred on the data. For instance, in data $\mathrm{C}$, data $\mathrm{G}$, data, $\mathrm{J}$ and data L. then, if we compare them into the similarities data, it will be C-G, C-J, C-L, G-J, G-L, J-L. It means that data C similar with data $\mathrm{G}$, data $\mathrm{C}$ similar with data $\mathrm{J}$ and so on. So, in four data (C-G-J-L) of zodiac killer letters which has been compared each other was found that there are six similar pairs (C-G, C-J, C-L, G-J, G-L, J-L). Furthermore, the other similarities pattern occurred between two data which only has constant theme pattern, those are data D and data I. so the comparison between two data of data D and data I has only one similar pair. Then the last similarities between two data which has constant theme and linear theme but no multiple theme pattern has occurred in data $\mathrm{E}$ and data $\mathrm{K}$. In this case also there is only one similar pair from two data $\mathrm{E}$ and data $\mathrm{K}$.

Table 5. The percentage of thematic progression pattern

\begin{tabular}{|l|l|l|}
\hline TP Pattern & Total & Percentage \\
\hline Constant Theme & 32 & $65,30 \%$ \\
Linear Theme & 8 & $16,32 \%$ \\
Multiple Theme & 9 & $18,36 \%$ \\
\hline
\end{tabular}

Based on data above it has found a total of thematic progression is fourty nine patterns form constant theme, linear theme, and multiple theme of zodiac killer letters. the fourty nine is equals to $(100 \%)$ percent in total of all data zodiac killer letters. To find out the percentage of constant theme is the total of constant theme multiplied by total patterns thematic progression, then divided by one hundred (32x100:49). So, the percentage of constant theme which has occurred in zodiac killer letters is $65,30 \%$. To find out the percentage of linear theme is the total of linear theme multiplied by total patterns thematic progression, then divided by one hundred (8x100:49). So, the percentage of linear theme which has occurred in zodiac killer letters is $16,32 \%$. To find out the percentage of multiple theme is the total of multiple theme times by total patterns thematic progression, then divided by one hundred (9x100:49). The last percentage of multiple theme which has occurred in zodiac killer letters is $18,36 \%$.

The samples of data are presented below:

Table 6. Theme and Rheme based on data A

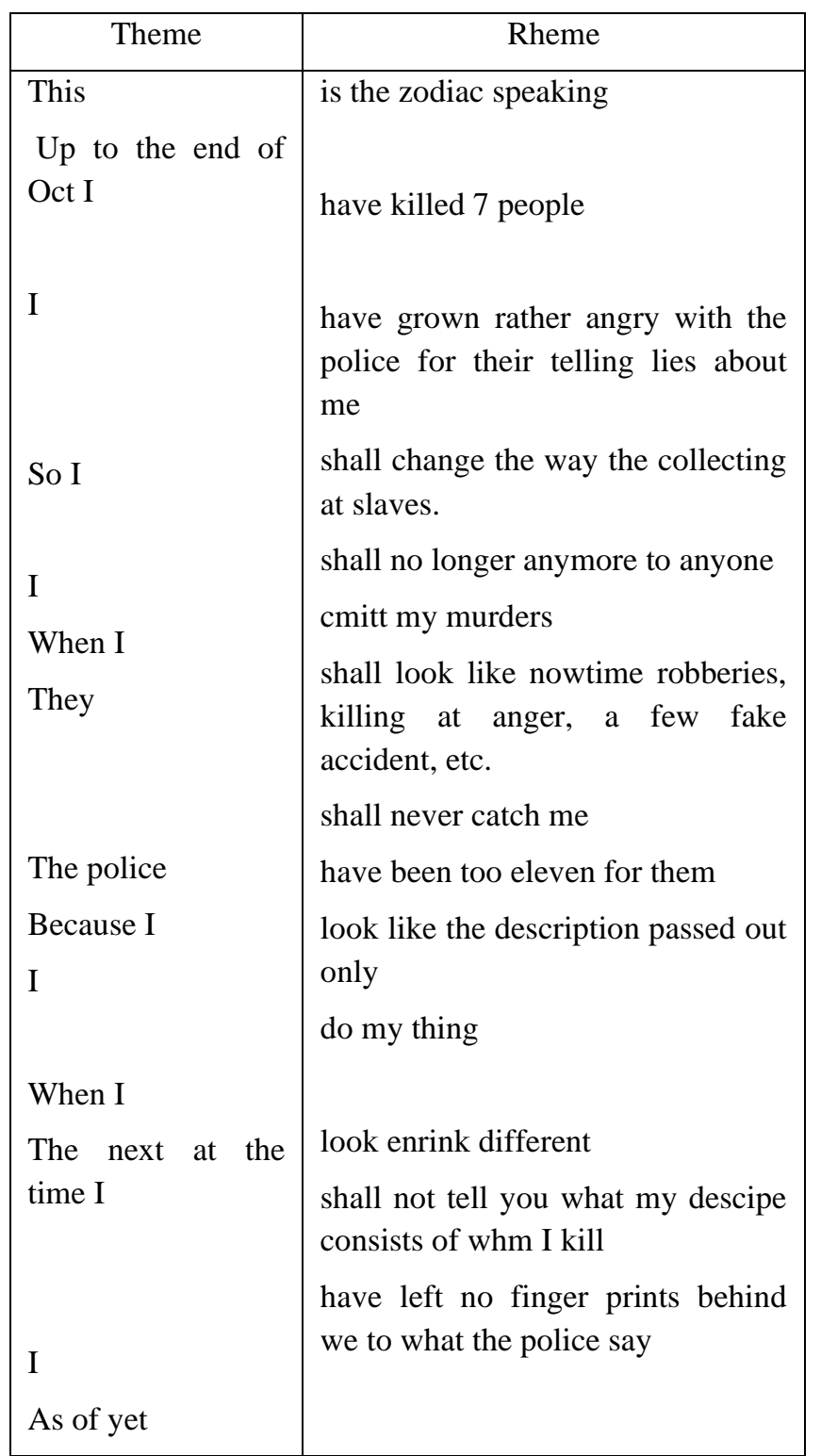




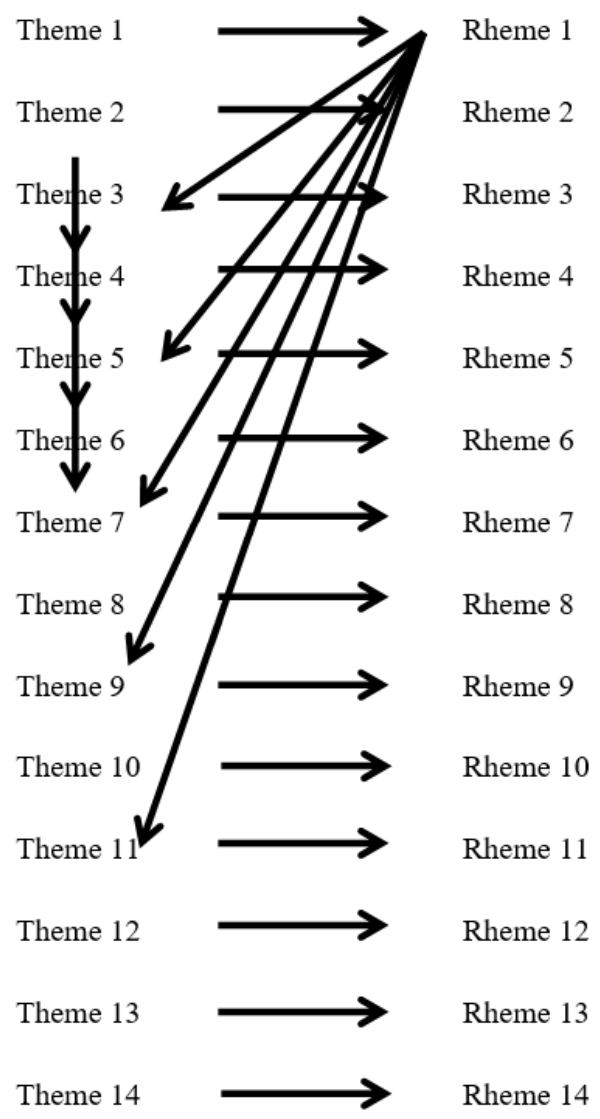

Fig.4: Thematic progression pattern based on data A

From the analysis above, it has found four constant theme, one multiple theme and no linear theme. The fisrt constant theme occurred from theme 2 to theme 3 . The first constant theme above explained that theme 2 at the second clause (up to the end of Oct I) refers to theme 3 at the third clause (I). It means that both theme 2 and theme 3 which has unmarked theme; nominal group; pronoun (I) indicated to the same person namely zodiac killer. Then, the same context of constant theme also occurred in theme 3 at the third clause (I) became theme 4 at the fourth clause ( so I), in theme 4 at the fourth clause (so I) to be theme 5 at the fifth clause (I), in theme 5 at the fifth clause (I) refers to theme 6 at the sixth clause (when I). Additionally, the meaning of theme at the begin of theme 2 until theme 6 which describes unmarked theme; nominal group; pronoun (I) is all same to indicate the same person too, those are zodiac killer. Moreover, multiple theme just appeared at once in this letter 1 , such in rheme1 at the first clause (is the zodiac speaking) that becomes theme 2 at the second clause (up to the end of Oct I), theme 3 at the third clause (I), theme 4 at the fourth clause (so I), theme 5 at the fifth clause (I) and theme 6 at the sixth clause (when I). It means that the meaning of rheme 1 at the first clause (zodiac speaking) refers to the unmarked theme; nominal group; pronoun (I) of each theme in the theme 2 at second clause, theme 3 at the third clause, theme 4 at fourth clause, theme 5 at the fifth clause and theme 6 at the sixth clause. Both the meaning of zodiac speaking and pronoun (I) those are indicate to zodiac killer.

Table 7. Theme and Rheme based on data $F$

\begin{tabular}{|l|l|}
\hline \multicolumn{1}{|c|}{ Theme } & \multicolumn{1}{c|}{ Rheme } \\
I & $\begin{array}{l}\text { is the Zodiac speaking } \\
\text { am still out here an crack proof } \\
\text { must you to know about my latest } \\
\text { slaves that } \\
\text { have collected about two weeks } \\
\text { ago up by see ma murder }\end{array}$ \\
I & $\begin{array}{l}\text { will give you clue to help you } \\
\text { with the mystry. }\end{array}$ \\
They & $\begin{array}{l}\text { were killed by a freeway } \\
\text { The Blue Meannies }\end{array}$ \\
The body count & $\begin{array}{l}\text { almost caught me } \\
\text { is growing now 100+ all over the } \\
\text { state of Ca and Na }\end{array}$ \\
\hline
\end{tabular}

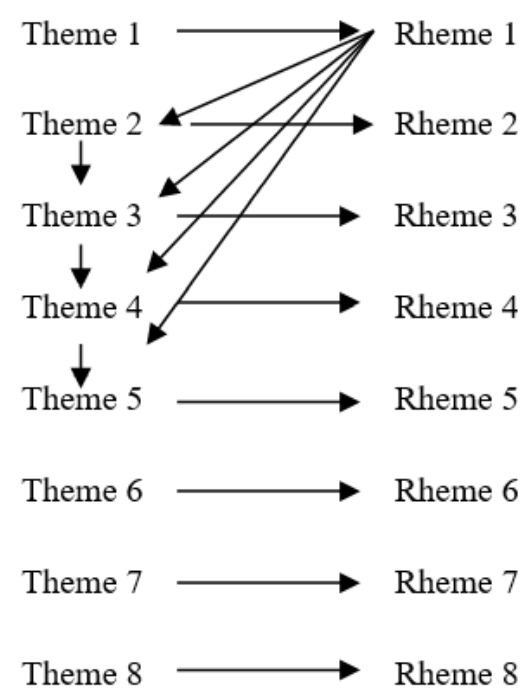

Fig.5: Thematic progression pattern based on data $F$

From the analysis above, it has found four constant themes, one multiple theme and no linear theme. The first constant theme occurred from theme 2 to theme 3 . The first constant theme above explained that theme 2 at the 
second clause (I) refers to theme 3 at the third clause (I). It means that both theme 2 and theme 3 which contain unmarked theme; nominal group; pronoun (I) indicated to the same person namely zodiac killer. Moreover, the same context of constant theme also occurred in theme 3 at the third clause (I) became theme 4 at the fourth clause (I). It also means that theme 3 and theme 4 have same meaning, those are zodiac killer. Then, third constant theme also continued from theme 4 at the fourth clause (I) became theme 5 at the fifth clause (Ca I). It also means that theme 4 and theme 5 which contain pronoun (I) have same meaning, those are zodiac killer. Furthermore, multiple theme just appeared at once in this letter 6 , such in rheme 1 at the first clause (is the zodiac speaking) that becomes theme 2 at the second clause (I), theme 3 at the third clause (I), theme 4 at the fourth clause (I), and theme 5 at the fifth clause ( $\mathrm{Ca} \mathrm{I}$ ). It means that the meaning of rheme 1 at the first clause (zodiac speaking) refers to the pronoun (I) of each theme in the theme 2 at second clause, theme 3 at the third clause, theme 4 at fourth clause and theme 5 at the fifth clause (Ca I). Both the meaning of zodiac speaking and pronoun (I) those are indicate to zodiac killer.

Table 8. Theme and Rheme based on data $H$

\begin{tabular}{|l|l|}
\hline \multicolumn{1}{|c|}{ Theme } & \multicolumn{1}{c|}{ Rheme } \\
\hline This & $\begin{array}{l}\text { is the murderer at the two } \\
\text { teenagers last christmass at Lake } \\
\text { Herman \& the girl on the } 4^{\text {th }} \text { of } \\
\text { July near the golf course in } \\
\text { Vallejo } \\
\text { killed them } \\
\text { shall state some facts which only } \\
\text { I \& the police know. }\end{array}$ \\
$\begin{array}{l}\text { To prove I } \\
\text { Christmass } \\
\text { brandname of ammo } \\
\text { super X 10 shots } \\
\text { The boy }\end{array}$ & $\begin{array}{l}\text { were fixed } \\
\text { was on his back with his feet to } \\
\text { the car }\end{array}$ \\
The girl & $\begin{array}{l}\text { was on her right side feet to the } \\
\text { west } \\
\text { was wearing patevned slacks } \\
\text { th July, girl } \\
\text { The boy } \\
\text { Brand name at } \\
\text { ammo }\end{array}$ \\
\hline
\end{tabular}

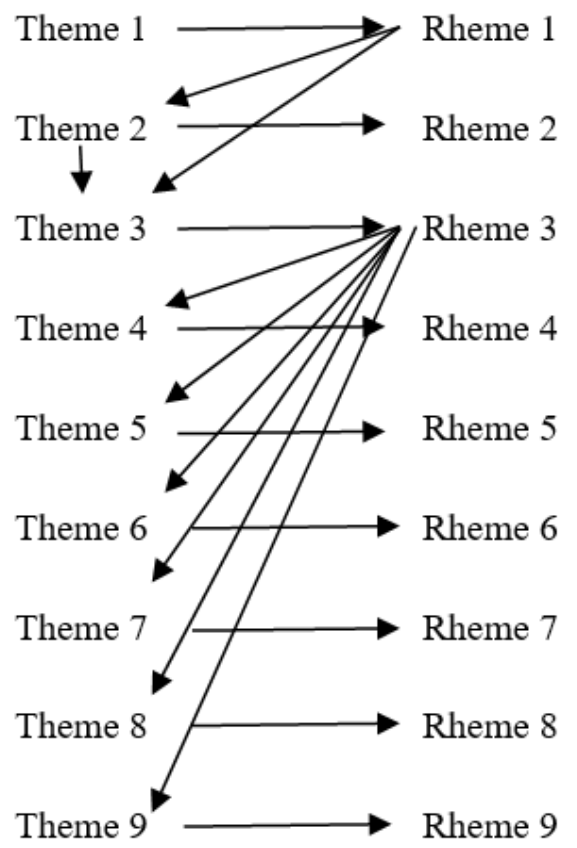

Fig.6: Thematic progression pattern based on data $H$

From the analysis above, it's found one constant theme, two multiple themes and no linear theme. The constant theme occurred from theme 2 to theme 3 . The constant theme above explained that theme 2 at the second clause (to prove I) refers to theme 3 at the third clause (I). It means that both theme 2 and theme 3 which contain unmarked theme; nominal group; pronoun (I) indicated to the same person namely zodiac killer. Furthermore, multiple theme appeared twice in this letter 8. Firstly multiple theme is occurred such as in rheme 1 at the first clause (is the murderer at the two teenagers last christmass at Lake Herman \& the girl on the 4th of July near the golf course in Vallejo) that became theme 2 at the second clause (to prove I), and theme 3 at the third clause (I). It means that the meaning of rheme 1 at the first clause (the murderer) refers to the subject pronoun (I) at phrase (to prove I) in the theme 2 at second clause, and it also same refers theme 3 at the third clause too.. Both the meaning of the murderer and pronoun (I) those are indicate to zodiac killer. Secondly, the multiple theme appeared in the rheme 3 at the third clause (shall state some facts which only I \& the police know) that became theme 4 at the fourth clause (Christmass brandname of ammo super X 10 shots), theme 5 at the fifth clause (the boy), theme 6 at sixth clause (the girl), theme 7 at the seventh clause (4th July, girl), theme 8 at the eighth clause (the boy), and theme 9 at the ninth clause (Brand name at ammo). It means that the meaning of rheme 3 at third clause is zodiac killer wants to describe and sort out a series of events and their victims to 
the reader or police at that time. So, the meaning of the rheme 3 refers to theme 4 at the fourth clause, theme 7 at the seventh clause, and theme 9 at the ninth clause, it means a series of events which including name of place and time. Moreover, the meaning of rheme 3 also refers to theme 5 at the fifth clause, to the theme 6 at the sixth clause, and to the theme 8 at the eight clause which means the victims (the boy and the girl) or teenagers who was killed by zodiac killer.

\section{CONCLUSION}

There are certain thematic progression written by zodiac killer. The findings reveal that the zodiac killer almost used multiple theme in every letters of zodiac killer. Based on the findings, the use of multiple theme ususally occurs in rheme one at the first clause. The most interesting is this multiple theme always refers to unmarked theme; nominal group; pronoun (I) who indicates to Zodiac killer. There are nine times total of zodiac killer has been using multiple theme. It indicated that he was really glad to mention his name and he wants the reader more notice with his message. Moreover, the constant theme is the most appearing pattern in thematic progression of zodiac killer letters. It proves by a total of constant theme that has thirty two in zodiac killer letters. It indicates that zodiac killer interest to tell the same thing in his writing. In addition, there are similarities of zodiac killer letters on each others like in some letters there are only using constant theme and multiple theme but no linear theme. Now we can conclude the similarities of thematic progression often occur in zodiac killer letters. It means that the zodiac killer letters are very possible written by one person. So it's a personal crime, not criminal group.

\section{REFERENCES}

[1] Creswell, J. W. (2012). Educational research. Pearson.

[2] Christie, F., \& Martin, J. R. (1997). Genre and institutions: Social processes in the workplace and school. London: Cassell.

[3] Fries, P. H.(2002) "Themes, Methods of Development, and Text”. In R. Hasan \& P. H. Fries. (Eds.). On Subject and Theme. A Discourse Functional Perspective

[4] Gerot, L., \& Wignell, P. (1994).Making sense of functional grammar.An introductory work book.Sydney: Gerd Stabler.

[5] Ghadessy, Mohsen.(1995) "Thematic development and its relationship to register and genres."Thematic Development in English Texts. Ed. M. Ghadessy. New York: Cassel, 1995.129-146.
[6] Halliday, M.A.K. (2014) An Introduction to Functional Grammar (4th ed.). Revised by C.M.I.M Matthiessen. New York: Routledge,

[7] Paltridge, B. (2006). Discourse analysis. An introduction. London: Continuum.

[8] Raddum (2010). Zodiac Killer Ciphers

[9] Richards, J. C. \& Schmidt, R. (2002).Longman dictionary of language teaching and applied linguistics (3rded.). Harlow: Longman.

[10] Saldana, J. (2011). Fundamentals of Qualitative Research. Oxford, New York: Oxford University Press.

[11] Thompson, G. (2014). Introducing functional grammar(3rd ed.). Abingdon: Routledge. 